\title{
Effects of Alcohol and Nicotine on Cytotoxic Functions of Human Lymphocytes ${ }^{1}$
}

\author{
Madhavan P. N. Nair, Ziad A. Kronfol, and Stanley A. Schwartz \\ Departments of Pediatrics, Epidemiology, and Psychiatry, The University of Michigan, \\ Ann Arbor, Michigan 48109
}

\begin{abstract}
The in vitro effects of the recreational drugs, ethanol (EtOH) and nicotine, on natural killer (NK) antibody-dependent cellular cytotoxic (ADCC) and lymphokine-activated killer (LAK) cell activities on normal lymphocytes were investigated. Lymphocytes precultured with EtOH at concentrations of 0.4 and $0.6 \%(\mathrm{v} / \mathrm{v})$ produced significant suppression of NK and ADCC activities. In target-binding assays, EtOH decreased the target-binding capacity of effector cells. EtOH also inhibited the activities of Percollseparated, NK-enriched large granular lymphocytes. EtOH-induced inhibition of NK activity could be reversed by incubating lymphocytes for $1 \mathrm{hr}$ with interferon. The generation and lytic capacity of LAK cells was also significantly depressed by EtOH when added at the initiation of culture. Nicotine at concentrations of 5 and $10 \mu \mathrm{g} / \mathrm{ml}$, when added directly to mixtures of effector and target cells, produced significant inhibition of NK activity. Nicotine $(2 \mu \mathrm{g} / \mathrm{ml})$ and EtOH $(0.01,0.1$, and $0.2 \%)$ at noninhibitory concentrations when added separately, showed significant suppression of NK activity when used in combination. Pretreatment of target cells with either EtOH or nicotine for $4 \mathrm{hr}$ did not affect cytotoxic activity. Inhibition of cytotoxicity was also not due to direct toxicity of effector cells because lymphocytes treated with either EtOH or nicotine showed normal ${ }^{51} \mathrm{Cr}$ release and their viability was comparable to that of untreated control cells. These studies demonstrate that $\mathrm{EtOH}$ and nicotine have significant immunomodulatory effects on the cytotoxic activities of human lymphocytes which may be of clinical relevance. 1990 Academic Press, Inc.
\end{abstract}

\section{INTRODUCTION}

High intake of recreational drugs such as alcohol and nicotine, the latter through cigarette smoking, is associated with increased infections and malignancies (1-5). Smokers have a higher risk of a variety of cancers such as carcinoma of the lungs, esophagus, and bladder (6) and excessive alcohol consumption may predispose the individual to head and neck cancer and HIV infection $(7,8)$. Previous studies suggested a general decrease in various immune functions in alcoholics and heavy smokers $(5,9-15)$.

Natural killer (NK) cells and lymphokine-activated killer (LAK) cell activities are believed to be early immune surveillance responses against nascent tumors and viral infections $(16,18)$. It was previously demonstrated that the NK activities of lymphocytes from alcoholics could be either decreased (9) or increased (19) compared to controls. These differences in activities may have been confounded

\footnotetext{
${ }^{1}$ This work was supported, in part, by NIH Grants 1 F50 AA07378, NIMH MH 42988, 2 ROI CA35922, NIH Biomedical Research Support Grant 2 S07 R405383, and grants from the American Diabetes Association-Michigan Affiliate, Michigan Memorial Phoenix Project and Hoffman LaRoche Inc., Nutley, NJ.
} 
by several cofactors, including smoking, malnutrition, or cirrhosis. However, very little is known about the effects of alcohol or nicotine on the cytotoxic activities of normal lymphocytes. The present investigation examines the direct, in vitro effects of alcohol and nicotine on NK, ADCC, and LAK cell activities of normal lymphocytes.

\section{MATERIALS AND METHODS}

\section{Experimental Design}

L-(-) Nicotine (Eastman Kodak Co., Rochester, NY) was diluted in Hanks' balanced salt solution (HBSS) to give final concentrations ranging from 0.1 to 10 $\mu \mathrm{g} / \mathrm{ml}$. Ethyl alcohol USP, absolute 200 proof (AAPER Alcohol and Chemical Co., Kentucky) was diluted in HBSS to give final concentrations ranging from 0.01 to $0.6 \%(\mathrm{v} / \mathrm{v})$. Drugs were added either directly to the reaction mixture containing effector and target cells or incubated with effector cells for 24 to $72 \mathrm{hr}$, washed, and tested for NK, ADCC, or target-binding functions. Controls containing target and effector cells without added drugs, or targets or effector cells plus drugs were examined concomitantly. In experiments to investigate the synergistic effect of drugs, alcohol and nicotine were added together to cultures which were examined for cytotoxic activities.

\section{Separation of Lymphocytes}

Mononuclear cells were isolated from heparinized $(20 \mathrm{U} / \mathrm{ml})$ venous blood obtained from healthy nonsmoking adults who had abstained from alcohol consumption for at least 1 week and who otherwise were moderate to low drinkers. Lymphocytes were separated by a modified method of Boyum (20). Donors were apprised of the study and consents were obtained consistent with the policies of The University of Michigan and the National Institutes of Health. Blood was diluted with an equal volume of normal saline and was centrifuged at $400 \mathrm{~g}$ for 30 min at $18^{\circ} \mathrm{C}$. The mononuclear cell band was harvested, washed three times with saline, and resuspended in RPMI 1640 medium containing $25 \mathrm{mM}$ Hepes buffer supplemented with $5 \%$ heat-inactivated fetal calf serum (FCS) (GIBCO, Grand Island, NY), $80 \mu \mathrm{g} / \mathrm{ml}$ gentamicin (Shering Corp., Kenilworth, NJ), and $300 \mu \mathrm{g}$ fresh glutamine/ml (complete medium).

Mononuclear cells were depleted of adherent cells by passage over a column of Sephadex G-10 beads (Pharmacia Fine Chemicals, Piscataway, NJ), equilibrated in the same medium. After $45 \mathrm{~min}$ of incubation at $37^{\circ} \mathrm{C}$, nonadherent peripheral blood lymphocytes (PBL) were washed out with one bed volume of medium at $37^{\circ} \mathrm{C}$. The cell recovery was $\sim 70 \%$ of the total input, and macrophage contamination as indicated by nonspecific esterase staining was less than $2 \%$.

\section{Percoll Fractionation of Lymphocytes}

Enrichment of NK effector cells using a discontinuous density gradient of Percoll (Pharmacia) was carried out as described (21). To prepare a discontinuous gradient, Percoll solution was mixed at various concentrations with RPMI 1640 medium, and 2-ml aliquots were gently layered into $15 \times 130-\mathrm{mm}$ round-bottomed 
glass tubes. PBL were layered on top of the gradient and were centrifuged at $300 \mathrm{~g}$ for $45 \mathrm{~min}$ at $20^{\circ} \mathrm{C}$. Six fractions, with the uppermost $37.5 \%$ Percoll and the lower $50.0 \%$ Percoll, were collected from the top with a Pasteur pipet and washed twice in RPMI 1640 medium. The least dense fraction banding at the $37.5 \%$ interface consistently showed the highest NK activity and was used as a source of NKenriched cells. Recovery of cells was $\sim 85 \%$ of the input, and viability always exceeded $95 \%$ by trypan blue dye exclusion.

\section{Incubation of Lymphocytes with Drugs}

PBL depleted of adherent cells or NK-enriched cells isolated on a Percoll gradient were suspended in complete medium in $5 \times 70$ - $\mathrm{mm}$ tissue culture tubes at a concentration of $1 \times 10^{6} \mathrm{cells} / \mathrm{ml}$ to which either EtOH or nicotine was added and incubated for 24,48 , and $72 \mathrm{hr}$ in a humidified environment of $5 \% \mathrm{CO}_{2}$ in air at $37^{\circ} \mathrm{C}$. A duplicate set of cultures without added drugs was included as controls. Cell viability was comparable with control cultures as determined by trypan blue dye exclusion and was not affected by nicotine concentrations of 0.1 to $10 \mu \mathrm{g} / \mathrm{ml}$ or EtOH at 0.01 to $0.6 \%(\mathrm{v} / \mathrm{v})$. Treated and control cultures were assayed for their target-binding activity and ability to mediate NK and ADCC functions. Evaporation of EtOH from our cultures was approximately $39 \%$ after the first $24 \mathrm{hr}, 48 \%$ after $48 \mathrm{hr}$, and $59 \%$ by the end of $72 \mathrm{hr}$ of culture as determined by gas chromatography.

\section{Tumor Target Cells}

The human erythroleukemia cell line, K562; the histiocytic lymphoma cell line, U937; the T leukemia cell line, HSB; and the B cell leukemia line, SB; were used as targets in cytotoxicity tests. K562, U937, and HSB are NK-sensitive targets while SB is an NK-resistant cell line when used in a $4-\mathrm{hr}{ }^{51} \mathrm{Cr}$ release assay. All target cells were maintained in complete medium. Target cells were passaged for $48 \mathrm{hr}$ and washed twice with complete medium. To 0.8 -ml aliquots of complete medium containing $5 \times 10^{6}$ tumor cells, $200 \mu \mathrm{Ci}$ of ${ }^{51} \mathrm{Cr}$ as sodium chromate (New England Nuclear, Boston, MA) was added as described $(18,22)$. The cells were incubated at $37^{\circ} \mathrm{C}$ for $1 \mathrm{hr}$ in a humidified atmosphere of $5 \% \mathrm{CO}_{2}$, in air with intermittent shaking. Following incubation, the cells were washed three times with complete medium and resuspended to a concentration of $1 \times 10^{6} \mathrm{cells} / \mathrm{ml}$.

\section{Assay for NK Activity}

NK activity was determined in a direct ${ }^{51} \mathrm{Cr}$-release assay as described previously $(18,22,23)$. Briefly, varying concentrations of viable effector cells in complete medium were added to triplicate cultures of ${ }^{51} \mathrm{Cr}$-labeled target cells in $0.2 \mathrm{ml}$ volumes in V-bottom microtitration plates (Dynatech Labs, Alexandria, VA). After centrifugation at $40 \mathrm{~g}$ for $2 \mathrm{~min}$, the cells were incubated at $37^{\circ} \mathrm{C}$ in a humidified atmosphere of $5 \% \mathrm{CO}_{2}$ in air for $4 \mathrm{hr}$. Percentage cytotoxicity was calculated as

$$
\% \text { Cytotoxicity }=\frac{\text { experimental release }- \text { spontaneous release }}{\text { total release }- \text { spontaneous release }} \times 100,
$$


where total release represents counts obtained in an aliquot of $2 \times 10^{4}$ target cells, and spontaneous release represents counts obtained from control wells containing only $2 \times 10^{4}$ target cells. The spontaneous release from target cells for all cytotoxicity assays was always less than $5 \%$ of total labeling. Cytotoxicity was also expressed as lytic units (LU) $/ 10^{7}$ effector cells, defined as the number of effector cells needed to yield $30 \%$ cytotoxicity of $1 \times 10^{4}$ target cells. LU were calculated from the cytotoxicity curve by using four different effector to target $(E: T)$ cell ratios for each test by linear regression analysis.

\section{Assay for $A D C C$}

ADCC activity was determined as described earlier $(18,22)$. Briefly, $50 \mu l$ of varying concentrations of effector cells was added to $50 \mu$ lof complete medium containing ${ }^{51} \mathrm{Cr}$-labeled SB target cells and $100 \mu \mathrm{l}$ of a $2 \times 10^{-4}$ dilution of rabbit anti-SB antisera previously found to yield maximal ADCC. Percentage ADCC activity was calculated as described above for NK activity, with the following exceptions. Spontaneous release represents counts released in control wells containing effector cells, labeled SB target cells, and media instead of anti-SB antibodies, and total release represents counts obtained in an aliquot of $1 \times 10^{4}$ ${ }^{51} \mathrm{Cr}$-labeled SB target cells. Percentage inhibition of NK and ADCC activities was calculated as

$$
\% \text { Inhibition }=\frac{\begin{array}{c}
\% \text { cytotoxicity of } \\
\text { control lymphocytes }
\end{array}-\begin{array}{c}
\% \text { cytotoxicity of } \\
\text { treated lymphocytes }
\end{array}}{\% \text { cytotoxicity of control lymphocytes }} \times 100 .
$$

\section{Target-Binding Assay}

The target-binding cell assay was used as described by Haliotis et al. (24). Lymphocytes were precultured with varying concentrations for EtOH for $72 \mathrm{hr}$, washed twice, mixed with a fivefold excess of K562 target cells, centrifuged at $150 \mathrm{~g}$ for $5 \mathrm{~min}$, and incubated at $37^{\circ} \mathrm{C}$ for $5 \mathrm{~min}$. After incubation, lymphocytetarget mixtures were transferred to ice, the pellets were gently resuspended, and the number of lymphocytes binding to tumor targets was determined microscopically with a hemocytometer.

\section{Generation of LAK Cells}

Commercially available recombinant IL2 (Collaborative Research, Inc., Bedford, MA) was diluted in complete medium and stored at $-70^{\circ} \mathrm{C}$ before use. IL2 concentrations of 5 to $10 \mathrm{U} / \mathrm{ml}$ in complete medium (LAK medium) were used to generate LAK cells. PBL were activated to generate LAK cells by in vitro incubation for 5 to 6 days in medium containing $\mathrm{EtOH}$ at concentrations of $0.1,0.2$, 0.4 , and $0.6 \%(\mathrm{v} / \mathrm{v})$ in upright $24-\mathrm{cm}^{2}$ flasks at a density of $1 \times 10^{6} \mathrm{cells} / \mathrm{ml}$ at $37^{\circ} \mathrm{C}$ in a $5 \% \mathrm{CO}_{2} / 95 \%$ air atmosphere as described (25).

\section{Assay for LAK Cell Activity}

The LAK cell assay was performed as described for the NK assay using a 4-hr 
${ }^{51} \mathrm{Cr}$ release technique $(18,22,23)$. A fixed number of viable effector cells in complete medium was added to triplicate cultures of ${ }^{51} \mathrm{Cr}$-labeled targets in $\mathrm{V}$ bottom microtitration plates (CoStar, Cambridge, MA). After centrifugation at $40 \mathrm{~g}$ for $2 \mathrm{~min}$, they were incubated at $37^{\circ} \mathrm{C}$ in a humidified atmosphere of $5 \% \mathrm{CO}_{2}$ in air for $4 \mathrm{hr}$. At the end of incubation, the plates were centrifuged at $400 \mathrm{~g}$ for 10 min and 100- $\mu$ aliquots were removed from each well, transferred to glass tubes, and read in a gamma counter. Percentage cytotoxicity was calculated as described for NK cells.

\section{Statistical Analysis}

The statistical significance of differences in mean values was determined by a single tail Student's $t$ test.

\section{RESULTS}

\section{Effect of EtOH on NK and ADCC Activities}

In view of the finding that alcoholics are more susceptible to various infections and malignancies (1-5) and since a potential relationship exists between AIDS and alcohol abuse $(7,8)$, we examined the direct effect of alcohol on the NK and ADCC activities of normal lymphocytes. Figure 1 shows the effect of EtOH on NK cell activities of lymphocytes precultured in alcohol-containing medium. EtOH at a final concentration of $0.1 \%$ produced a slight increase in NK activities (40\% cytotoxicity vs $36 \%$ cytotoxicity) against K562 target cells compared to untreated control cultures. EtOH at a $0.2 \%$ final concentration demonstrated a slight decrease in NK activity ( $21 \%$ cytotoxicity, $P=\mathrm{NS}$ ) compared to control

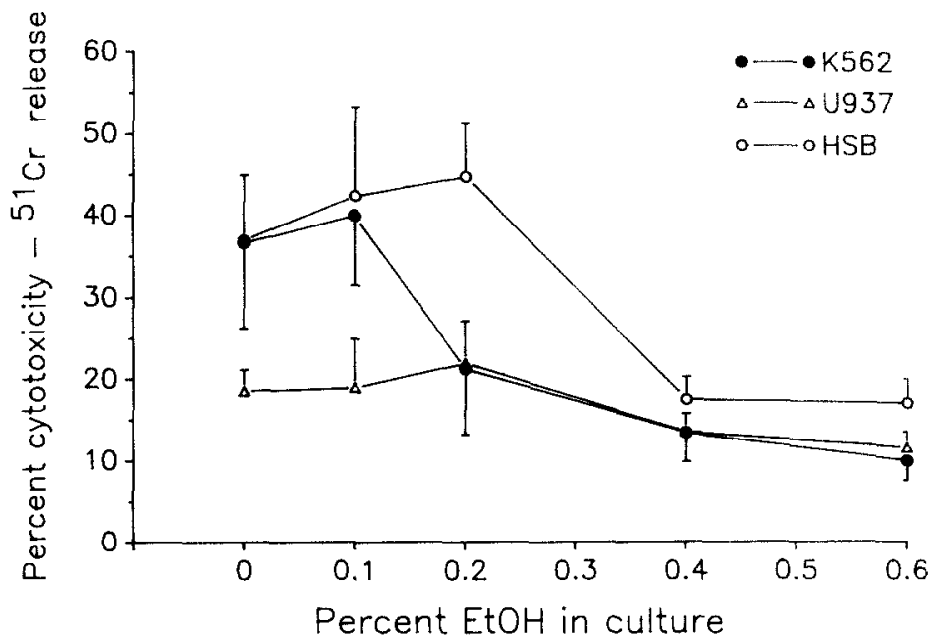

Fig. 1. Effect of EtOH on NK Activity. $1 \times 10^{6} \mathrm{PBL} / \mathrm{ml}$ was precultured with media containing varying concentrations of EtOH for $72 \mathrm{hr}$ at $37^{\circ} \mathrm{C}$ in a $5 \% \mathrm{CO}_{2}$ in air atmosphere. PBL were washed and tested for their cytotoxicity against different target cells at a 10:1 E:T cell ratio. The percentage cytotoxicity was calculated as under Materials and Methods. Values are the mean \pm SD of triplicate determinations from four separate experiments. 
cultures (36\% cytotoxicity). Lymphocytes precultured with EtOH at higher concentrations of 0.4 and $0.6 \%$ produced significantly decreased levels of NK activity (13.4\% cytotoxicity, $P<0.025$ and $9.9 \%$ cytotoxicity, $P<0.025$, respectively). PBL precultured with EtOH at 0.1 and $0.2 \%$ concentrations produced slight increases in NK activity (42 and 44\%, respectively) against HSB target cells compared to $37 \%$ cytotoxicity shown by control cultures. EtOH at 0.4 and $0.6 \%$ final concentrations, respectively, demonstrated $17.5 \%(P<0.05)$ and $17.0 \%(P<$ 0.025 ) cytotoxicity compared to $37 \%$ cytotoxicity produced by control cultures. PBL precultured in media containing $0.6 \% \mathrm{EtOH}$ manifested a lower level of cytotoxicity $(11.5 \%, P<0.05)$ against U937 target cells compared to $18.0 \%$ cytotoxicity produced by control cultures. EtOH at lower concentrations of 0.1, 0.2, and $0.4 \%$ did not produce significant inhibition of NK activity. Table 1 demonstrates the kinetics of inhibition of NK activity against K562 target cells by EtOH. PBL cultured with EtOH demonstrated a progressive suppression of NK activity. Suppression was noticeable at $24 \mathrm{hr}(84 \mathrm{LU}, P=\mathrm{NS})$ and $48 \mathrm{hr}(72 \mathrm{LU}, P=\mathrm{NS})$ and reached a peak at $72 \mathrm{hr}(53 \mathrm{LU}, P<0.05)$ compared to 98 and $84 \mathrm{LU}$ produced by control and EtOH-treated cultures at $0 \mathrm{hr}$. Figure 2 presents data on the effect of EtOH on the ADCC activities of lymphocytes against antibody-coated SB target cells. PBL precultured with increasing concentrations of $\mathrm{EtOH}(0.1,0.2$, 0.4 , and $0.6 \%$ ) produced dose-dependent inhibition of ADCC activities; inhibition was most significant at $0.4 \%(11 \%$ cytotoxicity, $P<0.05)$ and $0.6 \%(10 \%, P<$ $0.05) \mathrm{EtOH}$ concentrations compared to $18 \%$ cytotoxicity produced by control cultures.

Inhibition of the NK and ADCC activities of PBL precultured with EtOH at different $\mathrm{E}$ : $\mathrm{T}$ cell ratios is demonstrated in Table 2 . Cytotoxicity was dependent upon the number of effector cells used and the inhibitory effect of EtOH was observed at several E:T cell ratios. To determine whether EtOH affects the targetbinding capacity of the effector cells, an early event in the lytic process, targetbinding assays were performed (Table 3 ). EtOH significantly reduced target binding in a dose-dependent manner.

Data presented in Table 4 demonstrate the effect of EtOH on the NK activity of PBL in comparison with that of LGL. PBL precultured with $0.1 \% \mathrm{EtOH}$

TABLE 1

Kinetics of INHIBITION OF NK ACTIVITY BY EtOH ${ }^{a}$

\begin{tabular}{lcccc}
\hline $\begin{array}{c}\text { Treatment of } \\
\text { lymphocyte culture }\end{array}$ & \multicolumn{4}{c}{ Incubation time (hr) } \\
\cline { 2 - 5 } & 0 & 24 & 48 & 72 \\
None & $98.2 \pm 8.6^{b}$ & $88.0 \pm 10.3$ & $87.5 \pm 11.2$ & $82.6 \pm 13.0$ \\
& $(\mathrm{NS})^{c}$ & $(\mathrm{NS})$ & $(\mathrm{NS})$ & $(P<0.05)$ \\
$0.6 \% \mathrm{EtOH}$ & $84.6 \pm 11.2$ & $72.4 \pm 8.3$ & $68.7 \pm 6.8$ & $53.1 \pm 7.8$ \\
\hline
\end{tabular}

${ }^{a} 1 \times 10^{6} \mathrm{PBL} / \mathrm{ml}$ was precultured with $\mathrm{EtOH}$ at $0.6 \%$ final concentration for 0 to $72 \mathrm{hr}$ and tested for NK activity against K562 at a 10:1 E:T cell ratio.

${ }^{b}$ Results are the mean \pm SD of triplicate determinations of four separate experiments.

c Statistically not significant. 


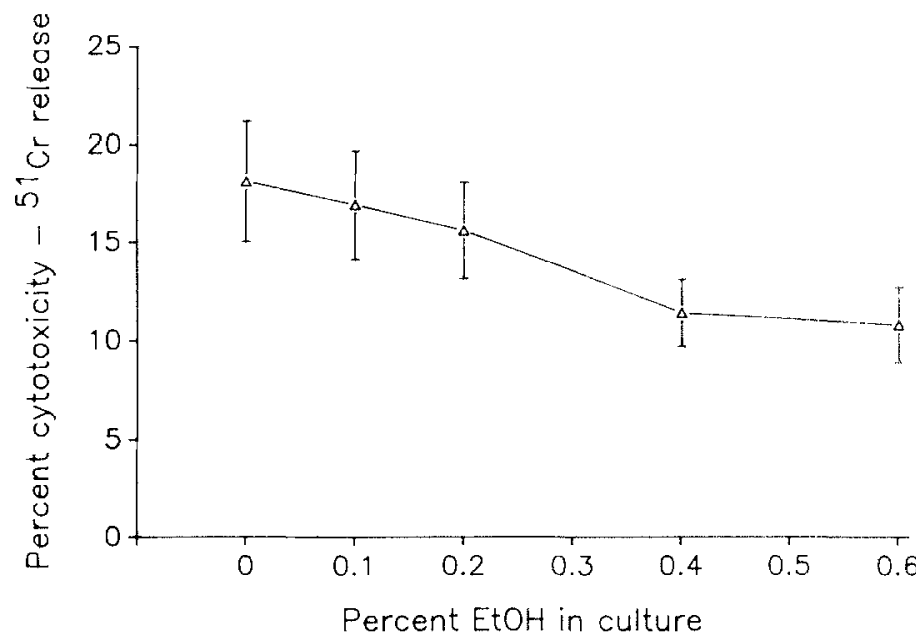

FIG. 2. Effect of EtOH on ADCC Activity. $1 \times 10^{6} \mathrm{PBL} / \mathrm{ml}$ was precultured with different concentrations of EtOH for $72 \mathrm{hr}$, washed, and tested against antibody-coated SB target cells at a 25:1 E:T cell ratio. Values are the mean \pm SDM of four separate experiments performed in triplicate.

demonstrated cytotoxicity comparable with that of control cultures. EtOH at 0.4 and $0.6 \%$ concentrations demonstrated significantly lower cytotoxicities of 12 and $10 \%$ compared to $19 \%$ cytotoxicity manifested by control cultures. Autologous LGL precultured in media demonstrated a significantly increased level of cytotoxicity (43.5\%) compared to PBL (19\%). LGL precultured with higher concen-

TABLE 2

EFFEct of EtOH on NK AND ADCC ACTIVITIES OF LyMPHOCYTES AT Different E:T Cell Ratios ${ }^{a}$

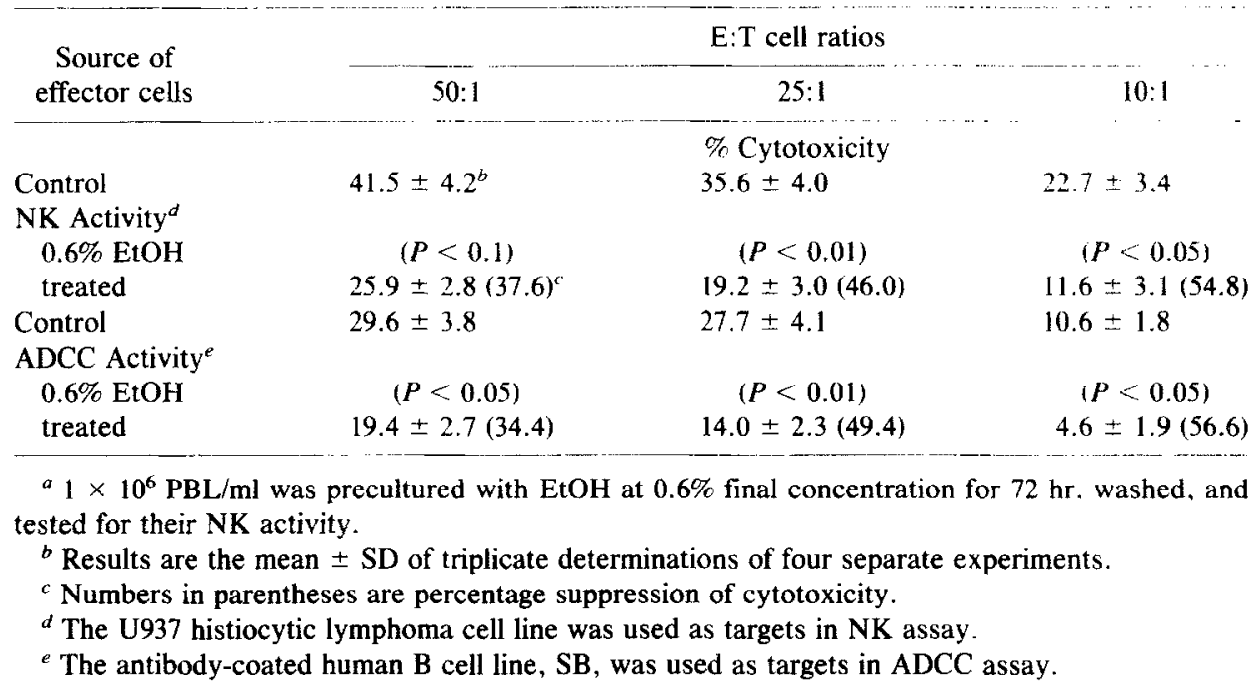


TABLE 3

EFFECT OF EtOH ON BINDING OF TARGET CELLS BY NK EFFECTOR LyMPHOCYTES ${ }^{u}$

\begin{tabular}{ccc}
\hline $\begin{array}{c}\text { EtOH } \\
\text { concentration } \\
(\% \mathrm{v} / \mathrm{v})\end{array}$ & Target-binding cells & $\begin{array}{c}\text { \% Inhibition of } \\
\text { target-binding cells }\end{array}$ \\
\hline 0 & $20.8 \pm 2.4$ & - \\
0.1 & $22.5 \pm 4.2$ & $-\mathbf{8 . 1}$ \\
0.2 & $18.8 \pm 3.0$ & 9.6 \\
0.4 & $13.0 \pm 1.5$ & $37.5(P<0.05)$ \\
0.6 & $11.0 \pm 1.1$ & $47.1(P<0.025)$ \\
\hline
\end{tabular}

${ }^{a}$ PBL precultured with different concentrations of EtOH for $72 \mathrm{hr}$, washed, and mixed with $\mathrm{K} 562$ target cells. Lymphocytes bearing at least one surface-bound target cell were counted in a hemocytometer. The results are expressed as the mean \pm SD of two experiments.

${ }^{b}$ Minus sign indicates enhancement.

trations of EtOH (0.4 and $0.6 \%)$ also showed significantly increased inhibition of NK activity, with cytotoxicities of 23 and $21 \%$, respectively.

\section{Effect of Nicotine on NK Activity}

In view of the finding that cigarette smoking is associated with a number of immune abnormalities, including reduction in NK activities $(3,5,11,27,28)$, we studied the in vitro effects of nicotine on NK functions. Data in Table 5 demonstrate that nicotine, when added directly at concentrations of 5 and $10 \mu \mathrm{g} / \mathrm{ml}$, significantly inhibited NK activity which was more pronounced at lower E:T cell ratios. On the basis of reports that lymphocytes from alcoholics and smokers demonstrate lower NK activity $(3,9)$, we also examined the combined effects of alcohol and nicotine at noninhibitory concentrations, when used separately, on the NK activity of PBL. The results presented in Fig. 3 show that EtOH alone at $0.01,0.1$, and $0.2 \%$ concentrations produced slight enhancement of the NK activity of PBL $(2,17$, and $8 \%$ cytotoxicity, respectively). Nicotine alone at 0.1 $\mu \mathrm{g} / \mathrm{ml}$, the lowest concentration, produced a slight enhancement $(15 \%)$ of NK activity, while at 1 and $2 \mu \mathrm{g} / \mathrm{ml}$ it caused negligible inhibition ( 2 and $8 \%$ inhibition,

TABLE 4

EFFECT OF EtOH on NK ACTIVITY OF PBL AND LGL ${ }^{a}$

\begin{tabular}{ccc}
\hline \multirow{2}{*}{$\begin{array}{c}\text { Treatment of } \\
\text { lymphocytes }\end{array}$} & \multicolumn{3}{c}{ \% Cytotoxicity } \\
\cline { 2 - 3 } & \multicolumn{1}{c}{ PBL } & LGL \\
\hline EtOH 0.1\% & $19.8 \pm 3.6$ & $43.5 \pm 8.6$ \\
EtOH 0.4\% & $20.9 \pm 3.9$ & $46.1 \pm 5.8$ \\
EtOH 0.6\% & $12.2 \pm 3.1(P<0.05)$ & $23.5 \pm 5.1(P<0.05)$ \\
\hline
\end{tabular}

a Lymphocytes were precultured with different concentrations of EtOH for $72 \mathrm{hr}$, washed, and tested for NK activity against K562 target cells at a 5:1 E:T ratio. LGLs were prepared on a discontinuous density gradient of Percoll as described (41). The fraction of lymphocytes banding at the $37.5 \%$ Percoll interface was used as LGL. Seventy-five to $80 \%$ of the cells of this fraction were positive to staining with the HNKI monoclonal antibody. Values are the mean \pm SD of four separate experiments performed in triplicate. 
TABLE 5

EFHECI OF Nicotine on NK ACTIVITY OF LYMPHOCYTEs

\begin{tabular}{clll}
\hline \multirow{2}{*}{$\begin{array}{c}\text { Nicotine } \\
\text { concentration } \\
(\mu \mathrm{g} / \mathrm{ml})\end{array}$} & \multicolumn{3}{c}{ Effector:target cells } \\
\cline { 2 - 4 } & \multicolumn{1}{c}{$50: 1$} & \multicolumn{1}{c}{$25: 1$} & \multicolumn{1}{c}{$10: 1$} \\
\hline Media control & $59.5 \pm 6.7^{b}$ & $54.7 \pm 6.0$ & $32.2 \pm 3.7$ \\
1 & $65.1 \pm 7.8(\mathrm{NS})^{c}$ & $52.5 \pm 8.7(\mathrm{NS})$ & $29.9 \pm 4.3(\mathrm{NS})$ \\
2 & $60.9 \pm 5.6(\mathrm{NS})$ & $48.6 \pm 4.1(\mathrm{NS})$ & $30.2 \pm 3.9(\mathrm{NS})$ \\
5 & $46.9 \pm 4.3(P<0.1)$ & $36.7 \pm 7.4(P<0.05)$ & $20.4 \pm 3.4(P<0.05)$ \\
10 & $31.9 \pm 4.5(P<0.01)$ & $25.3 \pm 3.1(P<0.0025)$ & $14.8 \pm 2.8(P<0.005)$
\end{tabular}

${ }^{a}$ Nicotine was added directly to the mixture of effector and U937 target cells in a $4-\mathrm{hr}{ }^{51} \mathrm{Cr}$ release assay.

${ }^{b}$ Values represent mean \pm SD of four separate experiments performed in triplicate.

${ }^{c}$ Statistically nonsignificant.

respectively) of NK activity. In mixing experiments, PBL precultured with $2 \mu \mathrm{g}$ nicotine/ml plus varying concentrations of $\mathrm{EtOH}(0.01,0.1$, and $0.2 \%)$ produced dose-dependent depression of the NK activity of PBL, with inhibitions of $22(P<$ $0.05), 31(P<0.05)$, and $43 \%(P<0.025)$, respectively, at $0.01,0.1$, and $0.2 \%$ EtOH concentrations. This suggests that EtOH and nicotine individually at noninhibitory concentrations produce significant suppression of NK activity when added in combination.

\section{Effect of EtOH on LAK Cell Generation}

Experiments were undertaken to investigate whether EtOH directly affects the activity of LAK cells or prevents their generation. Our results demonstrate that direct addition of EtOH at concentrations of $0.1,0.2,0.4$, and $0.6 \%$ to a mixture

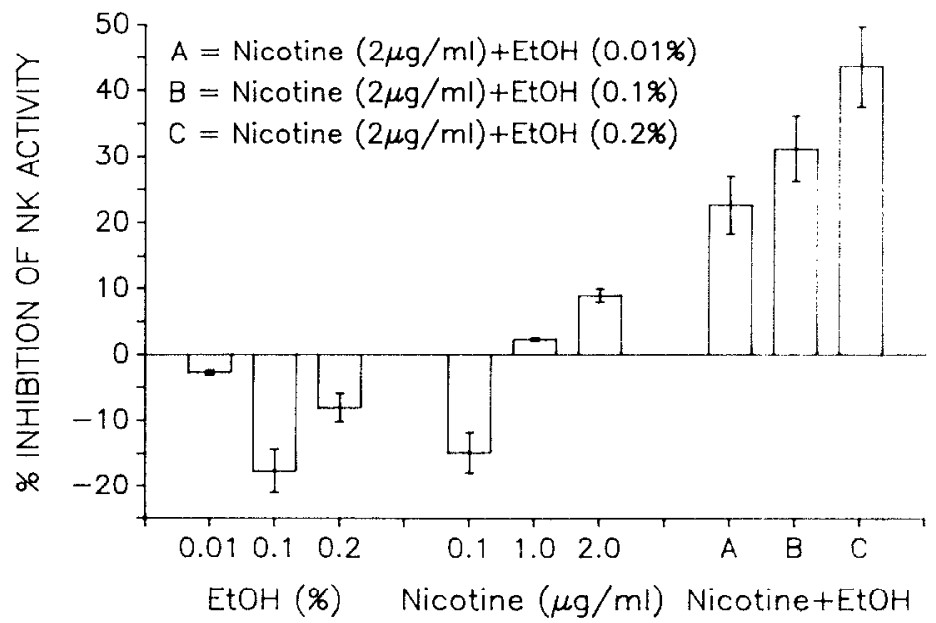

FIG. 3. Synergistic Effect of EtOH and Nicotine on NK Activity. $1 \times 10^{6} \mathrm{PBL} / \mathrm{ml}$ was cultured with $\mathrm{EtOH}$, nicotine, or EtOH + nicotine for $72 \mathrm{hr}$, washed, and tested for cytotoxicity against U937 target cells at a 25:1 E:T cell ratio. Inhibition of NK activity was calculated on the basis of the cytotoxicity produced by control cultures. Values represent the mean \pm SD of three separate experiments performed in triplicate. 
of effector and target cells did not affect the lytic capacity of LAK cells in a 4-hr assay period (data not presented). Table 6 shows the cytotoxic activity of LAK cells generated in the presence of different concentrations of EtOH against NKnonsensitive (SB) and NK-sensitive (HSB) targets. EtOH at 0.4 and $0.6 \%$ concentrations significantly inhibited LAK cell induction, yielding cytotoxicities of $128(P<0.025)$ and $87 \mathrm{LU}(P<0.025)$, respectively, compared to $152 \mathrm{LU}$ produced by control cultures against HSB targets and 18 and 17 LU compared to 35 LU manifested by control cultures against SB target cells.

\section{Effect of Interferon on Suppression of $\mathrm{NK}$ Activity by $\mathrm{EtOH}$}

We examined the role of interferon, an agent known to enhance NK activity, on the suppression of $\mathrm{NK}$ activity by EtOH (Table 7). Lymphocytes precultured in media alone and then treated with $500 \mathrm{U} / \mathrm{ml}$ of recombinant interferon- $\alpha$ for $1 \mathrm{hr}$ demonstrated enhancement of their NK activity (46\%) compared to the NK activity of lymphocytes cultured in media alone. Lymphocytes precultured with $0.4 \%$ EtOH demonstrated $22 \%$ cytotoxicity resulting in $30 \%$ suppression and this suppression was significantly reversed to only $4 \%$ by treatment with interferon for $1 \mathrm{hr}$. EtOH at a $0.6 \%$ concentration produced $41 \%$ suppression of NK activity which was reversed to $7 \%$ suppression by interferon treatment for $1 \mathrm{hr}$.

\section{DISCUSSION}

Earlier studies showed that chronic alcohol consumption was associated with humoral (29-31) and cellular $(4,32,33)$ immunologic abnormalities, including effects on suppressor (33-36), helper (37), and cytotoxic cell activities $(2,9,38$, 39). Cigarette smoking has also been shown to have a number of effects on the immune response of human lymphocytes such as Ig production $(11,27)$, alteration in the T4/T8 lymphocyte ratio $(11,27)$, reduced NK activity $(3)$, and depressed mitogen-induced lymphocyte transformation (15). Miller et al. (11) showed significant alterations in immunoregulatory $T$ cells, such as decreased levels of $\mathrm{CD}^{+}$and increased levels of $\mathrm{CD}^{+}$cells, in heavy smokers and these effects could be reversed upon cessation of smoking. Further, cigarette smoking has also

TABLE 6

EFFECT of EtOH on LAK CELl ACTIVITY ${ }^{a}$

\begin{tabular}{|c|c|c|}
\hline \multirow{2}{*}{$\begin{array}{l}\text { Treatment of } \\
\text { lymphocytes }\end{array}$} & \multicolumn{2}{|c|}{ Target cells } \\
\hline & HSB & SB \\
\hline & \multicolumn{2}{|c|}{ Cytotoxicity (lytic units) } \\
\hline 0 & $152.8 \pm 12.4^{b}$ & $35.7 \pm 6.7$ \\
\hline EtOH 0.1\% & $132.8 \pm 11.3$ & $28.7 \pm 8.3$ \\
\hline EtOH 0.2\% & $135.9 \pm 9.7$ & $31.7 \pm 9.4$ \\
\hline EtOH 0.4\% & $128.3 \pm 6.7(P<0.025)$ & $18.3 \pm 6.7(P<0.05)$ \\
\hline EtOH $0.6 \%$ & $87.6 \pm 5.3(P<0.025)$ & $17.9 \pm 6.8(P<0.025)$ \\
\hline
\end{tabular}

${ }^{a} 1 \times 10^{6} \mathrm{PBL} / \mathrm{ml}$ of media was precultured with recombinant IL2 $(5$ to $10 \mathrm{U} / \mathrm{ml}$ ) with or without different concentrations of EtOH for 5 to 6 days, washed, and tested against NK-resistant SB targets and NK-sensitive HSB targets at 10:1 E:T cell ratios.

${ }^{b}$ Values represent the mean $\pm \mathrm{SD}$ of three separate experiments performed in triplicate. 
TABLE 7

EFFECT OF INTERFERON (IFN) ON INHIBITION OF NK ACTIVITY BY EtOH ${ }^{a}$

\begin{tabular}{lcc}
\hline $\begin{array}{c}\text { Treatment of } \\
\text { effector cells }\end{array}$ & $\%$ Cytotoxicity & \% Suppression \\
\hline 0 & $32.7 \pm 4.9^{c}$ & - \\
IF $(500 ~ U)^{b}$ & $47.8 \pm 5.2$ & $46.1^{d}$ \\
EtOH 0.4\% & $22.6 \pm 5.0$ & 30.8 \\
EtOH 0.4\% + IF (500 U) & $34.3 \pm 4.6$ & 4.8 \\
EtOH 0.6\% & $19.2 \pm 3.9$ & 41.2 \\
EtOH 0.6\% + IF (500 U) & $30.4 \pm 4.8$ & 7.0 \\
\hline
\end{tabular}

${ }^{a}$ Lymphocytes were cultured alone or with EtOH for $72 \mathrm{hr}$, washed, and further treated with IF for $1 \mathrm{hr}$ and tested for their NK activity against $\mathrm{K} 562$ target cells at a 50:1 E:T cell ratio.

${ }^{b}$ Human recombinant $\mathrm{IFN}-\alpha$ was used at $500 \mathrm{U} / \mathrm{ml}$.

c Results are the mean cytotoxicity \pm SD of triplicate determinations of three separate experiments.

${ }^{d}$ Data represent percentage suppression of cytotoxicity compared to control cultures. Minus sign indicates enhancement.

been associated with increased levels of humoral mediators of stress such as catecholamines and corticosteroids (41). Previously we demonstrated that corticosteroids inhibit the NK activity of human lymphocytes (42). Also, we have reported that patients with a history of intravenous drug abuse, often associated with excessive alcohol consumption, demonstrated decreased levels of NK, ADCC, lectin-dependent cellular cytotoxicity, and interferon and interleukin 2induced NK activities (22).

We report herein that recreational drugs such as alcohol and nicotine can suppress NK, ADCC, and LAK cell activties of normal lymphocytes. However, this alcohol-induced suppression could be significantly reversed by IF. In the present investigation, suppression is operationally defined as the inhibition of effector cells after addition of drugs directly to the reaction mixture or after preculturing lymphocytes with drugs as indicated. The decrease in cytotoxicity observed was not due to toxic effecs of drugs on effector cells, as nicotine- and alcohol-treated cells showed levels of viability comparable to untreated control cultures. Also, lymphocytes precultured with drugs showed no increase in the spontaneous release of ${ }^{51} \mathrm{Cr}$ compared to untreated lymphocytes (data not presented). Suppression of cytotoxic activity is not likely due to effects of drugs on target cells since target cells treated with drugs for $4 \mathrm{hr}$ were as sensitive to lysis by effector cells as untreated control target cells. Direct addition of alcohol to mixtures of effector and target cells did not produce any significant inhibition of NK, ADCC, or LAK cell activities of lymphocytes (data not presented). Alcohol-induced suppression was dose dependent and required $72 \mathrm{hr}$ of preculture of lymphocytes with alcohol for maximum suppression (Table 1). NK activity showed a gradual decline over 24 to $48 \mathrm{hr}$ when lymphocytes were cultured with EtOH. Similar results were obtained in other experiments using higher E:T cell ratios, 50:1 and 25:1, and U937 and HSB target cells (data not presented). Further, lymphocytes maintained decreased levels of cytotoxicity even several hours after removing alcohol by washing (data not presented). Alcohol at lower concentrations (0.1 to $0.2 \%$ ) usually produced a slight but not significant enhancement of NK activity consistent with an earlier report (39), while alcohol at higher concentrations produced significant 
inhibition. Others have shown that the cytotoxic functions of blood monocytes and Kupffer cells were increased by alcohol at $0.4 \%$ concentration (40). This contrasts with the inhibitory effect of alcohol at similar concentrations on the NK functions of lymphocytes as reported herein. The apparent contradiction may be due to differential effects of alcohol on cells from various tissue origins or lineages. The mechanisms by which NK activity is slightly stimulated by lower concentrations of alcohol $(\mathbf{0 . 1 \%})$ are not well understood. It is possible that alcohol at lower concentrations may have a beneficial action on effector-target conjugation as demonstrated in Table 3, possibly resulting from changes in membrane fluidity and composition or receptor rearrangement on effector cells. Also, it is possible that lower concentrations of alcohol may positively affect the ability of cytolytic factors to mediate cytotoxicity by enhancing their release. However, these possibilities need further study.

Although alcohol levels in tissues and cell membranes may vary, a concentration of 0.3 to $0.4 \%$ in blood results in severe intoxication while $0.5 \%$ leads to coma. Chronic alcoholics may manifest greater suppressive effects of alcohol on cytotoxic activities because increased levels of alcohol are maintained over longer periods of chronic drinking. The results presented here demonstrate that alcohol at levels comparable with severe intoxication (0.4\%) suppresses NK and ADCC activities. As evaporation of $\mathrm{EtOH}$ in our cultures reduced the concentration by $59 \%$ after $72 \mathrm{hr}$, as quantitated by gas chromatography, the inhibitory effects of alcohol may occur at even lower levels than the starting concentration.

Only limited information is available on the immunoregulatory mechanisms affecting LAK cell activities. Previous studies (43) suggest that LAK cells may be derived from phenotypically heterogenous precursors. We recently reported that the generation and lytic capacity of LAK cells were significantly affected by Con A and prednisolone (25), demonstrating that, like other cell functions, LAK cell cytotoxicity is also under active immunologic control. The current study presents evidence that alcohol significantly inhibits the generation and lytic capacity of LAK cells (Table 6). However, alcohol, when added directly to a mixture of fresh LAK and target cells, did not cause any significant effects.

The level of nicotine in various body fluids may vary considerably. The plasma level of nicotine of moderate smokers (13.2 cigarettes/day) was estimated to be $15.7 \pm 10.1 \mathrm{ng} / \mathrm{ml}(44)$ and in heavy smokers ( 3 packs/day) up to $60 \mathrm{ng} / \mathrm{ml}$ (Ovid Pomerleau, University of Michigan, personal communication). The urine and saliva nicotine levels in moderate smokers (13.2 cigarettes/day) were found to be 1.84 and $0.476 \mu \mathrm{g} / \mathrm{ml}$, respectively (44). A recent paper suggests that increments in blood nicotine concentrations after the smoking of a single cigarette ranges from 5 to $30 \mathrm{ng} / \mathrm{ml}$ depending upon how the cigarette is used (45). Earlier studies estimated that heavy smokers maintain nicotine concentrations up to $0.28 \mu \mathrm{g} / \mathrm{ml}$ in the blood (46). However, acute levels of nicotine in smokers with a long smoking history may be much higher than the reported chronic blood levels. Previous studies have shown lower serum Ig concentrations and decreased levels of CD4 ${ }^{+}$ subsets in smokers $(11,27)$. Neher $(14)$ has shown that concentrations of nicotine up to $122 \mu \mathrm{g} / \mathrm{ml}$ produced decreased in vitro lymphocyte DNA synthesis in response to PHA stimulation without any toxicity, suggesting that cigarette smoking 
may affect cellular immunity. The nicotine concentrations used in the present study exceed levels reportedly attained in vivo by smokers. The present studies are our preliminary attempts to develop an in vitro model to examine the immunomodulatory effects of nicotine on human lymphocyte functions. However, these concentrations were not grossly toxic to lymphocytes as the viability of cells precultured with nicotine was similar to that of control cultures. Nicotine and alcohol at concentrations which did not affect NK activity when added alone produced a significant synergistic inhibitory effect on NK functions when added in combination. It is possible that this synergistic effect may be mediated through different mechanisms such as down-regulation of IL2 production, alteration of IL2 and NK receptors, and/or release of potential suppressive factors. This observation may have implications in vivo and may explain the reduced immunological responses often manifested by patients who are both alcoholics and smokers.

Interferon seems to play a major role in immunoregulation, including augmentation of NK activity in vitro and in vivo $(47,48)$. The current study demonstrates that EtOH-induced suppression of NK activity could be reversed with interferon. Several mechanisms for this effect are possible: Interferon may enhance target binding, activate pre-NK cells or precursor cells which are alcohol resistant, and/or activate mature NK cells rendered transiently inactive due to alcohol treatment. Elucidation of the mechanism(s) underlying the reversal of EtOH-induced immunosuppression by interferon awaits further investigation.

Similarly, the mechanisms by which alcohol or nicotine suppress cytotoxic functions are not fully understood. It is possible that these mechanisms may vary from target-binding to postbinding stages of the lytic process, including the production of soluble cytotoxic factor. Our studies demonstrate that alcohol significantly reduces the number of target-binding lymphocytes, suggesting that one mechanism may be directed at the early events of target lysis. It is possible that alcohol and nicotine may even have a stimulatory effect on suppressor cell subpopulations which regulate both NK and LAK cell functions. However, the effects of EtOH on postconjugate stages such as recycling ability or natural killer cytotoxic factor production by effector cells also remain to be studied.

Although the mechanisms of the immunomodulatory effects of alcohol and nicotine are not clearly understood, our present studies may provide an explanation for the proposed link between alcohol and nicotine and increased incidence of infections and malignancies. Smoking and alcohol consumption, an unfortunate common combination, are frequently associated with other risk factors for HIV infections. Thus the synergistic suppressive effects of nicotine and alcohol on immune responses may play a role in increasing susceptibility to AIDS.

\section{REFERENCES}

1. Pollak, E. S., Nomura, A. M. Y., Helburn, L. K., Stemmerman, G. N., and Green, S. B., Prospective study of alcohol consumption and cancer. N. Engl. J. Med. 310, 617-621, 1984.

2. Stacey, N. H., Inhibition of antibody dependent cell mediated cytotoxicity by ethanol. Immunopharmacology 8, 155-161, 1984.

3. Ferson, M., Edwards, A., Lind, A., Milton, G. W, and Hersey, P., Low natural killer cell activity 
and immunoglobulin levels associated with smoking in human subjects. Int. J. Canad. 23, 603609, 1979.

4. Mutchnick, M. G., and Lee, H. H., Impaired lymphocyte proliferative response to mitogen in alcoholic patients: Absence of a relation to liver disease activity. Alcohol. Clin. Exp. Res. 12, 155-158, 1988.

5. Hersey, P., Frendergest, D., and Edwards, A., Effects of cigarette smoking on the immune system: Follow up studies in normal subjects after cessation of smoking. Med. J. Aust. 2, 425, 1983.

6. Doll, R., and Peto, R., Mortality in relation to smoking: 20 years observations on male British doctors. Brit. J. 2, 1525-1536, 1976.

7. Siegel, L., AIDS: Relationship to alcohol and other drugs. J. Subst. Abuse Treat. 3, 271-274, 1986.

8. Stimmel, B., AIDS, alcohol and heroin: a particularly deadly combination. Adv. Alcohol Subst. Abuse 6(3), 1-5, 1987.

9. Charpentier, B., Franco, D., Paci, L., Charra, M., Martin, B., Vuitton, and Friss, D., Deficient natural killer cell activity in alcoholic cirrhosis. Clin. Exp. Immunol. 58, 107-115, 1984.

10. Lang, J. M., Ruscher, H., Hasselmann, J. P., Grandjean, P., Bigel, P., and Mayer, S., Decreased autologous rosette forming T lymphocytes in alcoholic cirrhosis. Int. Arch. Allergy Appl. Immunol. 61, 337-343, 1980.

11. Miller, L. G., Goldstein, G., Murphy, M., and Ginns, L. C., Reversible alterations in immunoregulatory $\mathrm{T}$ cells in smoking. Chest 82, 526-529, 1982.

12. Herskill, C. G., Miller, J. N., Aldrich, H. J., and Carpenter, C. M., Smoking and serologic abnormalities. J. Amer. Med. Assoc. 181, 674-677, 1962.

13. Corre, F., Lellonch, J., and Schwartz, D., Smoking and leukocyte counts. Lancet 2, 632-634, 1971.

14. Neher, G. H., Nicotine-induced depression of lymphocyte growth. Toxicol. Appl. Pharmacol. 27, 253-258, 1974.

15. Peterson, B. H., Steimul, L. F., and Callaghan, J. T., Suppression of mitogen-induced lymphocyte transformation in cigarette smokers. Clin. Immunol. Immunopathol. 27, 135-140, 1983.

16. Welsh, R. M., Natural cell-mediated immunity during viral infections. Curr. Top. Microbiol. Immunol. 92, 83-106, 1981.

17. Herberman, R. B., and Holden, T., In "Advances in Cancer Research," pp. 305. Academic Press, New York, 1978.

18. Nair, M. P. N., and Schwartz, S. A., Suppression of natural killer activity and antibodydependent cellular cytotoxicity by cultured human lymphocytes. J. Immunol. 126, 2221, 1981.

19. James, S. P., Hoffnagle, J. H., Jones, E. A., and Strober, W., Augmentation of natural killer cell function in vitro by interferon in primary biliary cirrhosis. Hepatology 2, 690, 1982.

20. Boyum, A., Isolation of mononuclear cells and granulocytes from human blood: Isolation of mononuclear cells by one centrifugation and of granulocytes by combining centrifugation and sedimentation. J. Clin. Lab. Invest. 21, Suppl. 97, 77, 1968.

21. Timonen, T., and Saksela, E., Isolation of human NK cells by density gradient centrifugation. $J$. Immunol. Methods 36, 285, 1980.

22. Nair, M. P. N., Laing, T. J., and Schwartz, S. A., Decreased natural and antibody-dependent cellular cytotoxic activities in intravenous drug abusers. Clin. Immunol. Immunopathol. 38, 6878, 1986.

23. Nair, M. P. N., Gray, R. H., Boxer, L. A., and Schwartz, S. A., Deficiency of inducible suppressor cell activity in the Chediak-Higashi syndrome. Amer. J. Hematol. 26, 55-66, 1987.

24. Haliotis, T., Roder, J., Klein, M., Ortaldo, J., Fauci, A. S., and Herberman, R. B., ChediakHigashi gene in humans. I. Impairment of natural-killer function. J. Exp. Med. 151, 1039, 1980.

25. Nair, M. P. N., and Schwartz, S. A., Immunoregulation of lymphokine activated killer cells. Clin. Immunol. Immunopathol. 49, 28, 1988.

26. Nair, M. P. N., Pottathil, R., Heimer, E.P. and Schwartz, S. A., Immunoregulatory activities of human immunodeficiency virus (HIV) recombinant proteins. I. Effect of HIV recombinant antigens and synthetic peptides on immunoglobulin synthesis and proliferative response of normal lymphocytes. Proc. Natl. Acad. Sci. USA 85, 6498, 1988. 
27. Gerard, J. W., Heiner, P. C., Mink, J., Meyers, A., and Dosman, J. A., Immunoglobulin levels in smokers and nonsmokers. Ann. Allergy 44, 261-262, 1980.

28. Friedman, G. D., Siegelaub, A. B., Seltzer, C. C., Feldman, R., and Collen, M. F., Smoking and leukocyte counts. Arch. Environ. Health 26, 137, 1973.

29. Delacroix, D. L., Elkon, K. B., Geubel, A. P., Hedgson, H. F., Dive, C., and Verman, J. F. Changes in size, subclass and metabolic properties of serum immunoglobulin $\mathrm{A}$ in liver diseases and in other diseases with high serum immunoglobulin A. J. Clin. Invest. 71, 358, 1983.

30. Drew, P. A., Clifton, P. M., Labrooy, J. T., and Shearman, D. J. C., Polyclonal B cell activation in alcoholic patients with no evidence of liver dysfunction. Clin. Exp. Immunol. 57, 479-486, 1984.

31. Morgan, M. Y., Ross, M. G. R., Ng, C. M., Adams, D. M., Thomas, H. L.. and Sherlock, S., HLA-B8, immunoglobulins and antibody responses in alcohol related liver diseases. J. Clin. Pathol. 33, 488, 1980.

32. Ericsson, C. D., Kohl, S., Pickering, L. K., Davis, G. S., and Faillace, L. A., Mechanisms of host defense in well nourished patients with chronic alcoholism. Alcoholism 4, 261, 1980.

33. Watson, R. R., Eskelson, C., and Hartman, B. R., Severe alcohol abuse and cellular immune functions. Ariz. Med. 10, 665-668, 1984.

34. Hodgson, H. J. F., Wands, J. R., and Isselbacher, K. J., Alteration in suppressor cell activity in chronic active hepatitis. Proc. Natl. Acad. Sci. USA 75, 1549, 1978.

35. Woltjen, J. A., and Zelterman, R. K., Suppressor cell activity in primary biliary cirrhosis. Gastroenterology 76, 1301, 1979.

36. Kawanishi, H., Tavassolie, H., MacDermott, R. P., and Sheagren, J. N., Impaired concanavalin A inducible suppressor $\mathrm{T}$ cell activity in active alcoholic liver disease. Gastroenterology 80, 510, 1981.

37. McKeever, U., Mahony, C. O., Whelan, C. A., Weir, D. G., and Feighery, C., Helper and suppressor $\mathrm{T}$ lymphocyte function in severe alcoholic liver disease. Clin. Exp. Immunol. 60, $39-48,1985$.

38. Abdallah, R. M., Starkey, J. R.. and Meadows, G. G., Alcohol and related dietary effects on mouse natural killer cell activity. Immunology 50, 131, 1983.

39. Saxena, Q. B., Nezey, E., and Adler, W. H., Regulation of natural killer activity in vivo. II. The effect of alcohol consumption on human peripheral blood natural killer cell activity. Int. J. Cancer 26, 413-417, 1980.

40. Sim, W. W., and Earnest, D. L., Ethanol stimulates or inhibits Kupffer cell functions dependent on its concentration in blood. In "Proceedings, 38th Annual Meeting of the American Association for the Study of Liver Disease, Chicago, IL," p. 1042, 1987.

41. Cryer, P. E., Heymond, M. W., Santiago, J. V., and Shah, S. D., Nerepinephrine and epinephrine release and adrenergic mediation of smoking associated hemodynamic and metabolic events. N. Engl. J. Med. 295, 573-577, 1976.

42. Nair, M. P. N., and Schwartz, S. A., Immunomodulatory effects of corticosteroids on natural killer and antibody-dependent cellular cytotoxic activities of human lymphocytes. J. Immunol. 132, 2876-2882, 1984.

43. Damle, N. K., Doyle, L. V., and Bradley, E. C., Interleukin 2-activated human killer cells are derived from phenotypically heterogeneous precursors. J. Immunol. 137, 2814, 1986.

44. Jarvis, M. J., Tunstall-Pedode, H., Feyerabend, C., Vesey, C., and Saloojee, J., Comparison of tests used to distinguish smokers and nonsmokers. Amer. J. Public Health 77, 1435-1438, 1987.

45. Benowitz, N. L., Pharmacologic aspects of cigarette smoking and nicotine addiction. N. Engl. J. Med. 319, 1318-1330, 1988.

46. Wolff, W. A., Hawkins, M. A., and Gilles, W. E., The spectrophotometric estimation of nicotine in the blood. J. Biol. Chem. 175, 825-831, 1968.

47. Johnson, H. M., and Blalock, J. E., Interferon immunosuppression: Mediation by a suppressor factor. Infect. Immun. 29, 301, 1980.

48. Nair, M. P. N., and Schwartz, S. A., Suppression of human natural and antibody dependent cytotoxicity by soluble factors from unstimulated normal lymphocytes. J. Immunol. 129, 2511$2518,1982$.

Received March 15, 1989; accepted with revision October 6, 1989 